\title{
FUZZY MONTE CARLO SIMULATION OPTIMIZATION FOR SELECTING MATERIALS IN GREEN BUILDINGS
}

\author{
Mohamed MARZOUK $\mathbb{D}^{*}$ \\ Structural Engineering Department, Faculty of Engineering, Cairo University, Giza, Egypt
}

Received 06 February 2019; accepted 27 December 2019

\author{
Highlights \\ Maximizing LEED credits for Construction Materials. \\ Providing decision making tool for selecting construction materials. \\ > Modeling cost uncertainty of green technologies.
}

\begin{abstract}
Global interest in sustainable and green building design has been increasing in the last few decades. This interest is strengthened by the fact that sustainable measures help in reducing negative social and environmental impacts of buildings. For that, this paper aims to develop a mixed integer optimization model that aids architects/designers and owner representatives during design stage in selecting building materials taking into consideration costs and risks that are involved in the selection process. The model is developed as a simulation optimization tool based on the Leadership in Energy and Environmental Design (LEED) rating system for new construction. The developed model allows deterministic and probabilistic cost analysis of various design alternatives. In addition, it identifies the least possible cost to gain the LEED credits and the risks associated with materials' quantities and materials' unit prices. To illustrate the use of the proposed tool, a case study of an office building project constructed in Egypt is presented. An integrated Fuzzy Monte Carlo Simulation (FMCS) analysis is performed to account for the associated risks of using new materials in the considered case study. The proposed model is capable to capture the cost uncertainty of building materials and to identify the cost and sustainability performance of various building materials by relating the LEED rating system for new construction.
\end{abstract}

Keywords: Fuzzy Monte Carlo Simulation, green buildings, LEED, optimization, materials cost, risk management, sustainability.

\section{Introduction}

There are many definitions of sustainable development worldwide. Clayton (1993) defines a sustainable development as "a pattern of resource use that aims to meet human needs while preserving the environment so that these needs can be met not only in the present, but also for future generations". The essence of this development is to reach to a balanced relationship between human activities and the natural environment (Clayton, 1993). Sustainable development aims to meet the present requirements without substantially compromising the ability our descendants to meet their future needs and requirements (WCED, 1987). Several studies have been made to help designer and decision makers in applying sustainability standards in building design. These studies tried to develop models to optimize life cycle cost and select alternatives to achieve green building certification (e.g., LEED, BREEAM). In the early design stage, decision makers can improve building performance at an optimum cost. Sustainable construction in addition to considering several aspects such as procurement, assembly, and commissioning, it addresses matters such as tendering, site planning and organization, material selection, recycling as well as wastes minimization (Langston, 2008).

Langston (2008) reported seven principles of sustainable construction that would ideally direct decision making during each phase of the design and construction process continuing throughout the building's entire life cycle. The principles include: 1) reducing resources consumption (Reduce), 2) reusing resources (Reuse), 3) using recyclable resources (Recycle), 4) protecting nature (Nature), 5) Eliminating toxins (Toxins), 6) applying life-cycle cost assessment, and 7) focusing on quality (Quality). It is common for project owners to have doubts in implementing

*Corresponding author. E-mail: mm_marzouk@yahoo.com 
new sustainable designs that can be attributed to: 1) high upfront costs of most new green technologies, 2) high risk associated with commissioning these technologies, and 3) uncertainties in these technologies' cost savings claims throughout the buildings' life cycle.

Material take-off refers to a list of all the materials utilized in the construction and their quantities. The material quantity take-off represents an important part of the cost estimate because the material cost represents a large portion of the total project cost. Consequently, the uncertainties associated with the material take-off and the material cost are a matter of major concern in case of fast track projects and adopting new technologies. Moreover, dealing with these uncertainties plays a very important role in providing an accurate cost estimate of construction projects.

A lot of research efforts have been carried out to study material selection problem using different methods such as multi-objective optimization (Sirisalee et al., 2004; Ashby, 2000; Zhou et al., 2009; Marzouk et al., 2013), ranking methods (Jee \& Kang, 2000; Chan \& Tong, 2007), indexbased methods (Holloway, 1998; Giudice et al., 2005), and other quantitative methods (Farag, 2014; Menassa, 2011; Wang et al., 2005). Menassa (2011) introduced a financial pricing method to supplement the traditional net present value techniques to assess the feasibility of the sustainable retrofits investments for existing buildings taking into consideration lifecycle uncertainties of costs, and benefits of the undertaking. Wang et al. (2005) presented an object-oriented framework that addresses green optimization problems namely hierarchical variables and coupling with simulation programs through the implementation of genetic algorithms. They examined the trade-off between life-cycle cost and life-cycle environmental impacts for green designs. The criterion for optimizing sustainability not only considers environmental impacts, economic impacts, and customer requirements, but also the market demand. Therefore, decision makers are capable of selecting the appropriate materials.

Ljungberg (2007) proposed a method to capture the subjective factors that arise in the decision-making process. The subjective factors used to describe the sustainable materials was assessed with the support of images. Visual features may broaden decision-making capabilities by allowing a process of evaluating more data without overloading the decision maker (Lurie \& Mason, 2007). Through visual recognition and human's highly developed skills of perceptual senses, decision makers could reduce large data sets to a set of simplified visuals that leads to an enhanced decision-making process (Heijungs et al., 2010). The assessment of sustainability perceptions among construction professionals may help in determining how do decision-makers actually perceive a product to be sustainable and what factors are involved in the selection. Castro-Lacouture et al. (2009) developed a model based on mixed integer linear program (MILP) to improve green construction decision making by considering both design and budget constraints to address realistic scenarios experienced by the decision maker. It is reported that the current sustainable building literature lacks of a method that helps decision makers select the appropriate materials considering all the factors that arise in the decision-making process in order to maximize sustainability in buildings (Ljungberg, 2007; Heijungs et al., 2010; Franzoni, 2011; Marzouk et al., 2018; Sameer \& Bringezu, 2019). In addition, it lacks a method that could help the architects/ designers to provide the optimal selection of materials, while considering environmental goals via a standard and recognized method, and meeting design and budget requirements at the same time.

The objective of this research is to develop a mixed integer optimization model that incorporates the selection of materials alternatives, cost and the cost uncertainty of these selections. The model is developed as a simulation optimization software system based on the Leadership in Energy and Environmental Design (LEED) rating system for new construction. A framework is developed for the purpose of guiding the decision makers, including architects/designers and owner representatives, in the selection of the optimum material alternative through the planning and design processes. The proposed model has novel aspects including: 1) trading-off between the cost and sustainability of building materials, 2) capturing the uncertainties that are associated with building materials, and 3) minimizing the total cost and cost uncertainty of the selected materials. The model allows the deterministic and probabilistic analysis of costs for various design alternatives, which makes it a tool that can identify the least possible cost of obtaining the LEED certification.

\section{Model formulation}

This section presents the formulation of the objective function that takes into consideration total materials cost and the target credits. Castro-Lacouture et al. (2009) have presented a model that considers nine building systems with a single objective function LEED credits. The proposed model was based on a modified LEED rating system for buildings in Colombia. They applied their model to a case study of a building in Colombia where the developed model can help decision makers to create a plan for the materials that they can use and the extent of their use. Table 1 lists the special credit name, number, intent and requirements of the LEED Rating System for New Construction and Major Renovations associated with the material selection of the project and the points awarded for fulfilling each credit. Total materials cost is calculated based on their direct cost using Eq. (1):

$$
\operatorname{Min} T M C=\sum_{j=1}^{m} \sum_{i=1}^{n_{j}} x_{j i} c_{j i},
$$

where: $x_{j i}$ is binary decision variable that specifies the use of design alternative $i$ for building component and $j$ for 
Table 1. Credits of Material Selection according to LEED Rating System (USGBC, 2009)

\begin{tabular}{|l|c|c|l|}
\hline \multicolumn{1}{|c|}{ Area } & $\begin{array}{c}\text { Credit } \\
\text { Number }\end{array}$ & $\begin{array}{c}\text { Credit } \\
\text { Points }\end{array}$ & \multicolumn{1}{|c|}{ Credit Name } \\
\hline $\begin{array}{l}\text { Sustainable } \\
\text { sites }\end{array}$ & 7.2 & 1 & Heat island effect \\
\hline \multirow{3}{*}{$\begin{array}{l}\text { Materials \& } \\
\text { Resources }\end{array}$} & 5 & $1-2$ & $\begin{array}{l}\text { Recycled Content } \\
(10-20 \%)\end{array}$ \\
\cline { 2 - 4 } & 6 & 1 & $\begin{array}{l}\text { Regional Materials } \\
(10-20 \%)\end{array}$ \\
\cline { 2 - 4 } & 7 & 1 & Rapidly Renewable \\
Certified Wood
\end{tabular}

building system, and $c_{j i}$ is the cost for the material alternative. $\mathrm{m}$ represents the total no. of the building systems. $n_{j}$ represents the no. of components within a system $j$. $T M C$ represents total cost of the project. It worth noting that the system refers to the name of the BOQ items. Whereas, the component refers to the utilized materials in the BOQ items.

The optimization problem aims at maximizing the accomplished $L E E D$ credits and minimizing the total material cost. The constraint, given in Eq. (2), allows the decision makers to target specific LEED credits. 13 building systems are considered: 1) wood components, 2) construction wood, 3) adhesives and sealants, 4) paints and coating, 5) carpets systems, 6) roofing systems, 7) glazing structure, 8) windows and skylight, 9) steel doors, 10) ceiling tiles, 11) floor finishing, 12) steel structure, and 13) brick units.

$$
\operatorname{Max} L E E D=\sum_{j=1}^{m} \sum_{i=1}^{n_{j}} y_{j i} z_{k} \geq L,
$$

where: $L$ is the target $L E E D$ credit point, $y_{j i}$ binary variable takes the value 1 if the material is used, otherwise, it takes 0 value; $z_{k}$ is credit points) $i$ for building component and $j$ for building system. $m$ represents the total no. of the building systems. $n$ represents the no. of components within a system $j$. MaxLEED represents number of $L E E D$ credit points of the project.

Furthermore, the model has several constraints that allow the following:

- Imposing lower and upper limits on the fraction of each building system using materials from a specific category.

- Imposing a maximum number of materials that can be chosen to build each system.
- Considering the LEED-based requirements as per Table 1.

\section{Fuzzy Monte Carlo simulation modeling}

Monte Carlo Simulation is used to model the uncertainty regarding the simulation model inputs (materials' quantities and unit prices). One of the methods that can be used to estimate the probability of an event is the frequency of that event occurring in a number of experiments (Pedrycz \& Gomide, 1998; Sadeghi et al., 2010). If the number of previous experiments was not large enough to conclude the probabilistic distributions, the need of the expert's opinion will be required to fill this information's gap. However, there is some difficulty in performing probabilistic analysis on subjective and linguistically expressed data (Goldstein, 2006; Akadiri et al., 2013). Akadiri et al. (2013) proposed a model that guides the selection of sustainable building materials. The proposed model can be utilized in selecting building material, through the use of the fuzzy extended analytical hierarchy process (FEAHP) techniques. Their proposed technique focused on addressing the issues of sustainability-based assessments, and the process of prioritizing relevant assessment criteria. Their model is highly complex and computationally demanding, Furthermore, it lacks the integration with multiple criteria decision making (MCDM) methods.

Zadeh (1965) introduced the fuzzy set theory to deal with uncertainty and vagueness of activities and problems. Fuzzy logic has been used successfully for representing such uncertainties in construction projects. In practice, an approach that can handle both random and fuzzy uncertainties is necessary. The literature is rich with research acknowledging the power of combining fuzzy logic with traditional simulation techniques (Antucheviciene et al., 2015; Raoufi et al., 2016; Kim, 2017). Antucheviciene et al. (2015) examined applicable decision-making methods developed to deal with uncertainties of civil engineering problems, with a focus on MCDM by means of fuzzy logic and stochastic modelling. Their research focused on green buildings, building information modelling, health, and safety aspects of the built environment. They concluded that the combination of fuzzy logic and MCDM methods can greatly enhance the decision-making process in the area of sustainability and green construction. Raoufi et al. (2016) examined the advantages of integrating widely used simulation and fuzzy logic techniques in modeling construction systems. Such combination can powerfully deal with both systems complexities and subjective uncertainties. They also presented a framework for the suitable coupling of the two techniques. Kim (2017) discussed the inefficiency of Monte Carlo Simulations (MCS) affected by experts' subjective uncertainties, through the manifestation of uncertainties in a single probability distribution. Accordingly, he introduced a fuzzy MCS approach to overcome for the previously mentioned inefficiencies, which produce a family of distributions, thus has an advantage in dealing with 
epistemic uncertainties. The proposed model represents a framework that can deal with both probability and fuzzy uncertainties. FMCS is implemented because the Monte Carlo Simulation fails to deal appropriately with the subjective and the linguistic data. FMCS is a combination between the fuzzy set theory and the probability theory in order to deal with the input uncertainties of the Monte Carlo simulation model (Zheng et al. 2019; Khishtandar, 2019; Peña et al., 2018). The sources of information about the construction projects may differ. Consequently, some input parameters of the project may be in the form of the probability distributions while others may be in the form of fuzzy membership functions.

A FMCS can be used to analyze risk in problems that contain both fuzzy and random inputs (Sadeghi et al., 2010). For random variables $\left(R_{i}\right)$ and subjective variables as fuzzy sets $\left(F_{i}\right)$, the proposed model $(M)$ can be expressed as per Eq. (3):

$$
Y=M\left(R_{1}, \ldots, R_{n}, F_{1}, \ldots, F_{m}\right) .
$$

Fuzzy arithmetic is performed to calculate the output in the form of a fuzzy set as per Eq. (4):

$$
\begin{aligned}
& M(r 11, \ldots ., r n 1, F 1, \ldots, F m) \rightarrow Y 1 \\
& M(r 12, \ldots, r n 2, F 2, \ldots, F m) \rightarrow Y 2 \\
& \vdots \\
& M\left(r_{1 w}, \ldots, r_{n w}, F_{w}, \ldots, F_{m}\right) \rightarrow Y_{w},
\end{aligned}
$$

where: $M$ represents the model that incorporates both random variables and fuzzy sets, $r$ represents the random variables of the model and they are represented by probability distributions. $F$ represents the fuzzy sets and they are represented by membership functions. $R$ indicates the probability distributions. $Y$ represents the output of the model.

The developed model uses the FMCS to simulate the uncertainty of the input data which are the quantities and unit prices of the materials. The materials' unit prices and quantities' uncertainties can be attributed to time limitations in fast track projects. The model optimizes the percentage used from each system's alternatives to achieve the optimization. Robati et al (2019) used the Monte Carlo simulation method to predict the embodied $\mathrm{CO}_{2}$-e emissions ranges. The simulation was applied on one case study which was the net-zero energy building at the University of Wollongong. The probability distributions of the most influential building materials was used to estimate the mean embodied $\mathrm{CO}_{2}$-e emissions value of each of the building materials. Then using MCS produced the function for the whole life embodied carbon emission of the building.

Although the effect of material selection on the sustainability of buildings was highlighted by numerous papers, they are not thoroughly investigating materials selection parameters. Further, few papers focused on other aspects like health and safety (e.g., Antucheviciene et al.,
2015). Other literature like Robati et al. (2019) were more of an assessment for material selection for existing buildings. Even the few sustainable material-selection focused models, such as Akadiri et al. (2013), suffered from disadvantages that limited their applicability, or Castro-Lacouture et al. (2009) which was a single objective function limiting its use as well. This highlights the need for the proposed sustainable materials selection aiding model that integrates MCDM methods to overcome the downsides of existing models.

\section{Case study}

In order to verify the performance of the developed model and to demonstrate its use, a case study of $21000 \mathrm{~m}^{2}$ LEED Gold Certified office building constructed in Cairo is analyzed. It is a four-story building consisting of ground floor, three typical floors ( $3000 \mathrm{~m}^{2}$ each), and two underground parking floors $\left(4500 \mathrm{~m}^{2}\right.$ each). The construction of the building was completed in December 2009 and it started operation in January 2010. The building accommodates 1200 employees and it has gold level according to LEED rating system for new construction. It has been reported that the building has saved in energy consumption cost, chilled water consumption cost, and domestic water consumption cost. Table 2 lists the 13 systems of the administrative building. It shows building systems, systems ID, quantities, and units. Probabilistic distributions are used to express the uncertainty regarding those variables.

Table 3 lists the building system, material alternatives, unit cost distribution for each alternative, solar reflectance

Table 2. Building systems and their respective quantitates

\begin{tabular}{|c|l|l|c|}
\hline ID & \multicolumn{1}{|c|}{ System Name } & \multicolumn{1}{|c|}{ Quantity } & Unit \\
\hline 1 & $\begin{array}{l}\text { Wood Components } \\
(\text { W })\end{array}$ & Uniform (2200-2300) & $\mathrm{m}$ \\
\hline 2 & $\begin{array}{l}\text { Construction Wood } \\
(\text { CW })\end{array}$ & Uniform (11900-12000) & $\mathrm{m}^{2}$ \\
\hline 3 & $\begin{array}{l}\text { Adhesives and sealants } \\
(\text { AS })\end{array}$ & Uniform (120-130) & Gal. \\
\hline 4 & $\begin{array}{l}\text { Paints and Coatings } \\
(\text { PC) }\end{array}$ & Uniform (720-725) & Gal. \\
\hline 5 & Carpet System (C) & Uniform (6750-6800) & $\mathrm{m}^{2}$ \\
\hline 6 & Roofing System (R) & Uniform (2670-2700 & $\mathrm{m}^{2}$ \\
\hline 7 & $\begin{array}{l}\text { Structural Glazing } \\
(\text { SG) }\end{array}$ & Uniform (5680-5700) & $\mathrm{m}^{2}$ \\
\hline 8 & $\begin{array}{l}\text { Windows and } \\
\text { Skylights (WS) }\end{array}$ & Uniform (3680-3700) & $\mathrm{m}^{2}$ \\
\hline 9 & $\begin{array}{l}\text { Steel Doors and } \\
\text { Frames (SD) }\end{array}$ & Uniform (205-210) & $\mathrm{m}^{2}$ \\
\hline 10 & Ceiling Tiles (CT) & Uniform (16100-16200) & $\mathrm{m}^{2}$ \\
\hline 11 & Flooring Finish (F) & Uniform (1480-1520) & $\mathrm{m}^{2}$ \\
\hline 12 & Structural Steel (SS) & Uniform (1,680-1,720) & Ton \\
\hline 13 & Masonry Units (MU) & $\begin{array}{l}\text { Uniform (10,000- } \\
10,100)\end{array}$ & $\mathrm{m}^{2}$ \\
\hline
\end{tabular}


Table 3. Characteristics of materials alternatives

\begin{tabular}{|c|c|c|c|c|c|c|c|c|c|c|c|c|c|}
\hline System & Material & Unit Price & $\mathrm{P} 1$ & $\mathrm{P} 2$ & P3 & $\mathrm{P} 4$ & P5 & P6 & P7 & P8 & P9 & P10 & P11 \\
\hline \multirow{2}{*}{$\begin{array}{l}\text { Wood } \\
\text { Components } \\
(\mathrm{W})\end{array}$} & Archi-Touch & Tri. $(1270,1274,1280)$ & - & 0.35 & 0 & 0 & 1 & - & - & - & 1500 & 0.2 & 1 \\
\hline & Mobica & Tri. $(760,770,790)$ & - & 0 & 0 & 0 & 0 & - & - & - & 1200 & 0 & 1 \\
\hline \multirow{5}{*}{$\begin{array}{l}\text { Construction } \\
\text { Wood (CW) }\end{array}$} & $\mathrm{CW}_{1}$ & Tri. $(345,350,355)$ & - & - & 0 & 1 & - & - & - & - & - & 0 & 1 \\
\hline & $\mathrm{CW}_{2}$ & Tri. $(395,400,405)$ & - & - & 0 & 0 & - & - & - & - & - & 0 & 0 \\
\hline & $\mathrm{CW}_{3}$ & Tri. $(445,450,455)$ & - & - & 1 & 1 & - & - & - & - & - & 0.3 & 0.8 \\
\hline & $\mathrm{CW}_{4}$ & Tri. $(245,250,255)$ & - & - & 1 & 0 & - & - & - & - & - & 0 & 0 \\
\hline & $\mathrm{CW}_{5}$ & Tri. $(345,350,355)$ & - & - & 1 & 1 & - & - & - & - & - & 0.5 & 0.8 \\
\hline \multirow{3}{*}{$\begin{array}{l}\text { Adhesives } \\
\text { and sealants } \\
\text { (AS) }\end{array}$} & BASF & Tri. $(22,24,26)$ & - & 0 & 1 & - & - & 700 & 750 & - & - & 0 & 1 \\
\hline & SIKA & Tri. $(14,16,18)$ & - & 0 & 1 & - & - & 850 & 750 & - & - & .4 & 1 \\
\hline & $\mathrm{CMB}$ & Tri. $(8,10,12)$ & - & 0 & 1 & - & - & 550 & 250 & - & - & 0 & 1 \\
\hline \multirow{3}{*}{$\begin{array}{l}\text { Paints and } \\
\text { Coatings } \\
\text { (PC) }\end{array}$} & Juton & Tri. $(23,25,27)$ & - & 0.5 & 1 & - & - & 0 & 150 & - & - & 0.6 & 0.8 \\
\hline & Terraco & Tri. $(16,18,20)$ & - & 0 & 1 & - & - & 150 & 100 & - & - & 0 & 1 \\
\hline & Sipes & Tri. $(13,15,17)$ & - & 0 & 1 & - & - & 250 & 150 & - & - & 0 & 1 \\
\hline \multirow{2}{*}{$\begin{array}{l}\text { Carpet } \\
\text { System (C) }\end{array}$} & Magtrad & Tri. $(175,177,180)$ & - & 0.06 & 1 & - & - & - & - & 215 & 500 & 0 & 1 \\
\hline & Interface & Tri. $(290,296,300)$ & - & 0.06 & 1 & - & - & - & - & 180 & 500 & 0 & 1 \\
\hline \multirow{3}{*}{$\begin{array}{l}\text { Roofing } \\
\text { System (R) }\end{array}$} & \begin{tabular}{|l|}
$\begin{array}{l}\text { Big white } \\
\text { gravel }\end{array}$ \\
\end{tabular} & Tri. $(20,22,24)$ & 87.5 & 0.95 & 1 & - & - & - & - & - & - & 0.1 & 0.3 \\
\hline & Grey Gravel & Tri. $(12,14,16)$ & 70 & 0.75 & 1 & - & - & - & - & - & - & 0 & 1 \\
\hline & $\begin{array}{l}\begin{array}{l}\text { Small white } \\
\text { gravel }\end{array} \\
\end{array}$ & Tri. $(28,30,32)$ & 72 & 0.2 & 1 & - & - & - & - & - & - & 0.3 & 0.9 \\
\hline \multirow{2}{*}{$\begin{array}{l}\text { Structural } \\
\text { Glazing (SG) }\end{array}$} & ALICO & Tri. $(1820,1826,1830)$ & - & 0.8 & 1 & - & - & - & - & - & - & 0 & 1 \\
\hline & ALUNILE & Tri. $(1970,1975,1980)$ & - & 0.65 & 1 & - & - & - & - & - & - & 0 & 1 \\
\hline \multirow{2}{*}{$\begin{array}{l}\text { Windows } \\
\text { and Skylights } \\
\text { (WS) }\end{array}$} & ALICO & Tri. $(245,250,255)$ & - & 0.25 & 1 & - & - & - & - & - & - & 0.3 & 0.3 \\
\hline & ALUNILE & Tri. $(195,200,205)$ & - & 0.1 & 1 & - & - & - & - & - & - & 0.5 & 0.9 \\
\hline \multirow{2}{*}{$\begin{array}{l}\text { Steel Doors } \\
\text { and Frames } \\
(\mathrm{SD})\end{array}$} & France Metal & Tri. $(540,550,560)$ & - & 0.45 & 0 & - & - & - & - & - & - & 0.3 & 0.5 \\
\hline & $\begin{array}{l}\text { Marryat \& } \\
\text { Scott }\end{array}$ & Tri. $(490,500,510)$ & - & 0.4 & 1 & - & - & - & - & - & - & 0.5 & 0.9 \\
\hline \multirow{4}{*}{$\begin{array}{l}\text { Ceiling Tiles } \\
(\mathrm{CT})\end{array}$} & AL BARAKA & Tri. $(55,57,60)$ & - & 0.5 & 1 & - & - & - & - & - & - & 0.2 & .4 \\
\hline & AL ZABY & Tri. $(49,51,53)$ & - & 0.7 & 1 & - & - & - & - & - & - & 0 & 1 \\
\hline & I.B.S & Tri. $(58,60,62)$ & - & 0.5 & 0 & - & - & - & - & - & - & 0.6 & 1 \\
\hline & $\begin{array}{l}\mathrm{AZ} \\
\text { International }\end{array}$ & Tri. $(40,43,45)$ & - & 0.6 & 1 & - & - & - & - & - & - & 0 & 1 \\
\hline \multirow{2}{*}{$\begin{array}{l}\text { Structural } \\
\text { Glazing (SG) }\end{array}$} & Archi-Touch & Tri. $(115,120,125)$ & - & 0.55 & 1 & - & - & - & - & - & - & 0.2 & 0.6 \\
\hline & Mobica & Tri. $75,80,85)$ & - & 0.75 & 1 & - & - & - & - & - & - & 0.2 & 0.8 \\
\hline \multirow{2}{*}{$\begin{array}{l}\text { Structural } \\
\text { Steel (SS) }\end{array}$} & AZZ & Tri. $(3645,3650,3655)$ & - & 0.1 & 1 & - & - & - & - & - & - & 0.2 & 0.5 \\
\hline & Bashy & Tri. $(3745,3750,3755)$ & - & 0.2 & 1 & - & - & - & - & - & - & 0 & 1 \\
\hline \multirow{3}{*}{$\begin{array}{l}\text { Masonry } \\
\text { Units (MU) }\end{array}$} & Camenta & Tri. $(73,75,77)$ & - & 0.5 & 1 & - & - & - & - & - & - & 0 & 1 \\
\hline & Toblat & Tri. $(83,85,87)$ & - & 0.4 & 1 & - & - & - & - & - & - & 0.2 & 0.4 \\
\hline & Samcret & Tri. $(63,65,67)$ & - & 0.7 & 1 & - & - & - & - & - & - & 0 & 1 \\
\hline
\end{tabular}


index, recycled content, regional materials percentage, content of volatile organic compounds, the lower limit of the material, and the upper limit of materials for each system. The uncertainty in the unit cost may be a result of uncertainty associated with labor productivity due to unexpected weather conditions (Ahuja et al., 1994). The table lists the characteristics of the alternative material of the building systems that could be used to achieve points for the special credits of the LEED rating system for new constructions and major renovations. The solar reflectance index is used to indicate the amount of sunlight reflected by the surface of the roofing material.

The percentage of the recycled content is based on the cost of the value of the material of the whole project. If $10 \%$ of the project is made of recycled material, then, the project earns 1 point in the rating system, and for an additional $10 \%$ another point is awarded. The percentage of the regional material is based on the cost of the value of the material of the whole project. If $10 \%$ of the project is made of material extracted, harvested, recovered, or manufactured regionally within 500 miles radius of the project site then the project earns 1 point in the rating system, and for an additional 10\% another point is awarded. Rapidly renewable material or products helps to earn another point when $2.5 \%$ of the project's value is made of material or products that are manufactured from plants that have a ten-year re-harvest cycle or shorter, one or two credits are acquired in case of $30 \%$ or $40 \%$ of the used furniture conform to the limitations of containing certain chemical groups, most notably the urea formaldehyde group. Up to 3 credit points are acquired for conforming to the limitations of volatile organic compounds (VOC) emissions and content. There are 7 categories to conform to; one point, two points, and 3 points are acquired if the new construction is compliant with the criteria of two, 4 and 5 of the 7 categories respectively. P6 to P11 of Table 3 lists the VOC characteristics of each of the construction's systems.
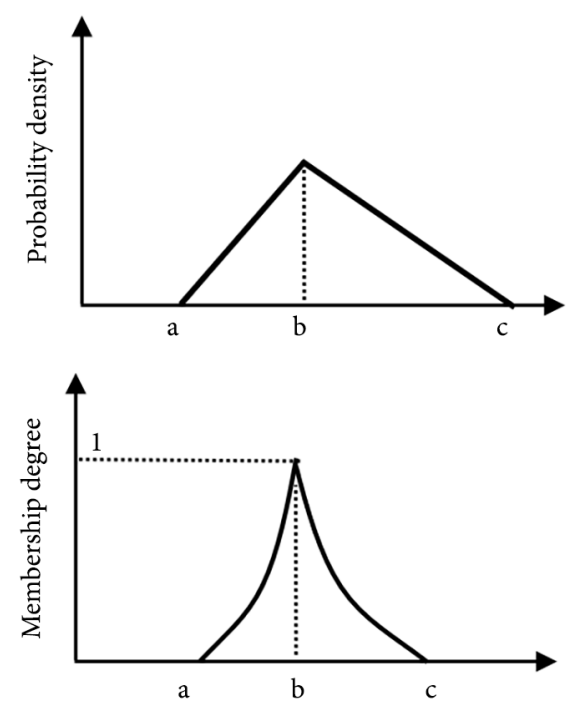

Figure 1. Transformation of the triangular distribution for the unit cost of One Wood Component (W) Materials
Figure 1 represents the transformation of the triangular distribution for the unit cost of the wood component (W) from Mobica in Table 3 to a fuzzy membership function based on Dubois et al. (2004). The FMCS model provides the mean quantities and their standard deviation for each material and their corresponding total cost distribution. Table 4 lists the fraction of each system to be utilized from the selected materials. The FMCS optimization performance chart is shown in Figure 2.

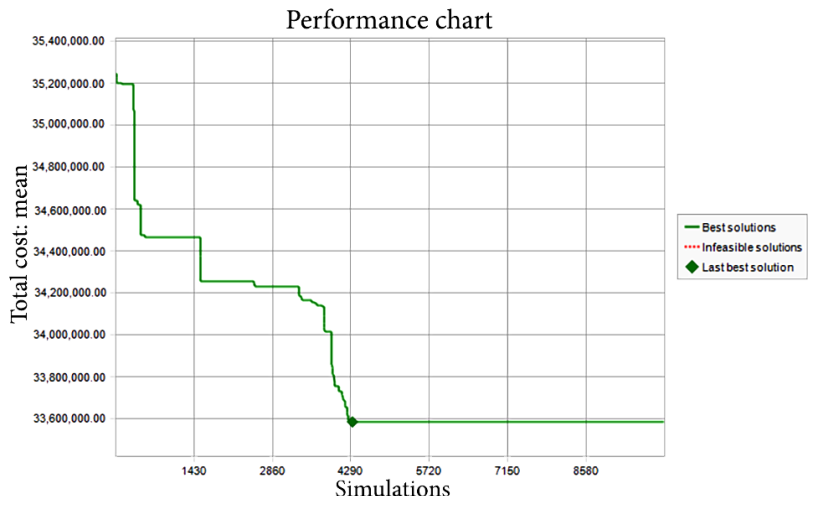

Figure 2. FMCS optimization performance

Table 4. Selected materials percent for each system

\begin{tabular}{|c|c|c|c|c|c|}
\hline \multirow{2}{*}{ System ID } & \multicolumn{5}{|c|}{ Alternative } \\
\cline { 2 - 6 } & 1 & 2 & 3 & 4 & 5 \\
\hline W & 0.377 & 0.623 & - & - & - \\
\hline CW & 0.0 & 0.0 & 0.3 & 0.0 & 0.7 \\
\hline AS & 0.0 & 0.4 & 0.6 & - & - \\
\hline PC & 0.6 & 0.4 & 0.0 & - & - \\
\hline C & 0.0 & 1 & - & - & - \\
\hline R & 0.4 & 0.3 & 0.3 & - & - \\
\hline SG & 1 & 0 & - & - & - \\
\hline WS & 0.3 & 0.7 & - & - & - \\
\hline SD & 0.3 & 0.7 & - & - & - \\
\hline CT & 0.2 & 0.0 & 0.6 & 0.2 & - \\
\hline SG & 0.6 & 0.4 & - & - & - \\
\hline SS & 0.0 & 1 & - & - & - \\
\hline MU & 0.0 & 0.4 & 0.6 & 0.0 & 0.0 \\
\hline
\end{tabular}

Table 5 lists the material alternatives that the model selected to optimize total materials cost, their quantities, and unit prices. This illustrates the model ability to select more than one alternative for the same system. For example, in the Construction wood (CW), the model selected $3589.8 \mathrm{~m}$ from alternative CW-3 and $8376.2 \mathrm{~m}$ from CW-5. Based on the materials costs, shown in Table 5, the mean total cost is calculated to be L.E 33,577,447 as shown in Figure 3. Although the solution shown in Table 5 satisfies design constraints, it achieved 9 out of the 11 LEED-based constraints. Therefore, further analysis is required to determine how to gain more points will add value to the decision-making process. Given the 


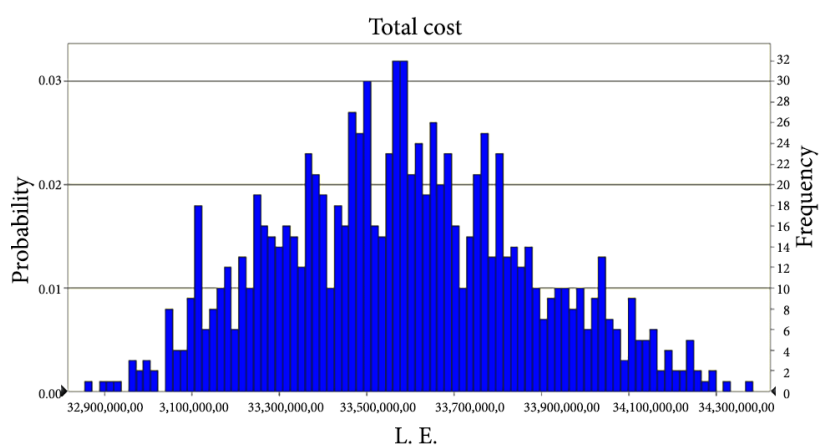

Figure 3. Total cost distribution obtained from simulation

uncertainty in material cost that ranges from $10 \%$ to $20 \%$, the model simulates several random scenarios for the cost. Out of such scenarios, the decision maker determines the probabilistic cost with the acceptable precision. In the herein case study, the probabilistic cost of 38,550,350 L.E. was obtained at ( $90 \%$ precision) as shown in Figure 4.

A further analysis is conducted to illustrate the proposed model effectiveness; the cost of a traditional concrete office building of similar features of the present case study is L.E 33,600,000. Meanwhile, the cost of the optimum solution taking into consideration the LEED credits and total cost as objective functions is L.E $33,577,447$. This demonstrates that there is no significant

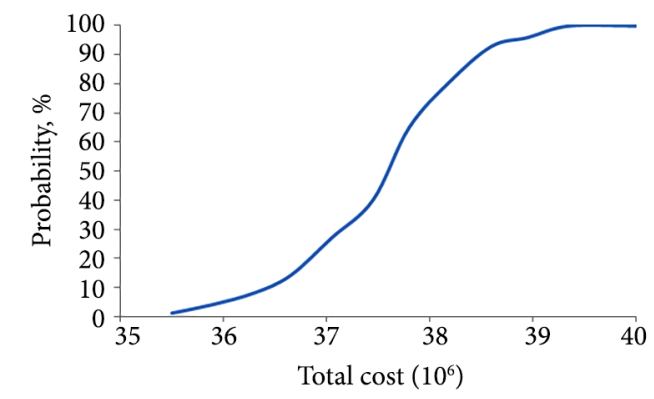

a) $\mathrm{k}=0$ (All the parameters are probabilistic)

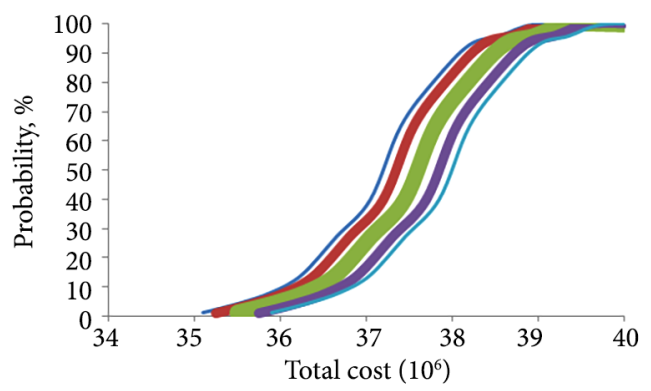

c) $\mathrm{K}$ (Fuzzy inputs) $=24$

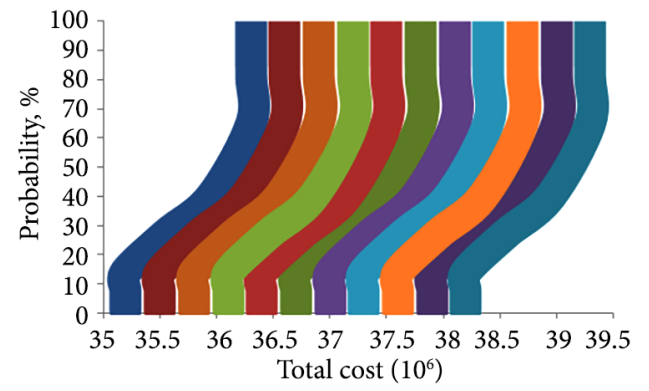

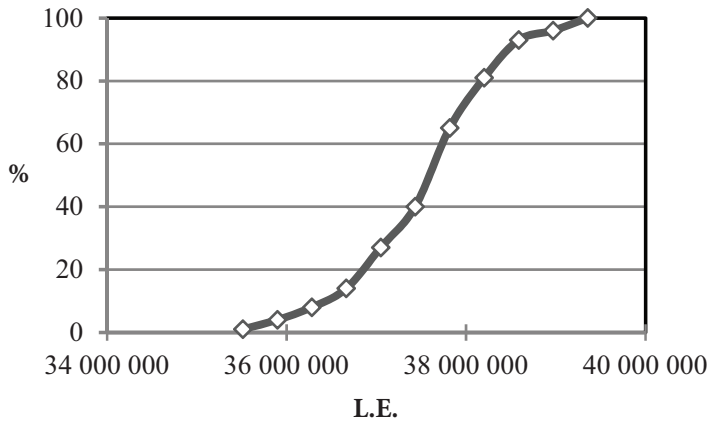

Figure 4. Probabilistic Material Cost Curve

escalation in the cost of the building. Nevertheless, there is a substantial increase in the earned LEED credits. Thus, the present case study is considered environmental and economical-effective, and consequently this demonstrates the distinct capabilities of the proposed model.

\section{Results and discussion}

The proposed methodology is capable to account for the associated risks of using new building materials using an integrated Fuzzy Monte Carlo Simulation (FMCS) analysis. Figure 5 illustrates the fuzzy CDFs graphs that depict how the fuzziness of the output increases in a proportional

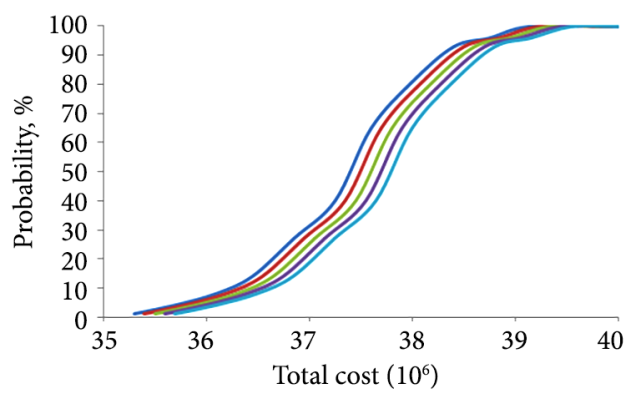

b) $\mathrm{K}$ (Fuzzy inputs) $=12$

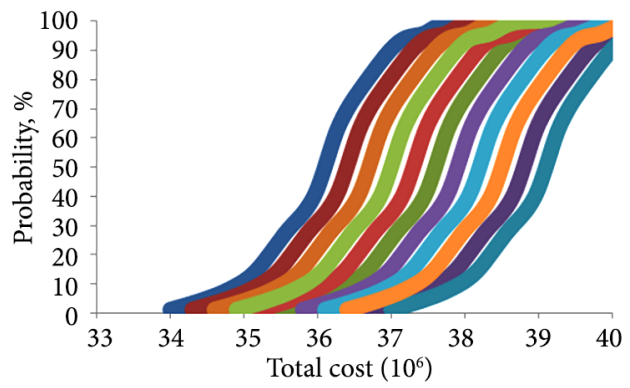

d) $\mathrm{K}$ (Fuzzy inputs) $=36$

e) $\mathrm{K}$ (Fuzzy inputs) $=48$

Figure 5. Total cost to probability output results 
Table 5. Case study selected materials

\begin{tabular}{|c|c|c|c|c|}
\hline $\begin{array}{l}\text { System } \\
\text { Name }\end{array}$ & $\begin{array}{c}\text { Material } \\
\text { Alternative }\end{array}$ & $\begin{array}{l}\text { Quan- } \\
\text { tity }\end{array}$ & $\begin{array}{l}\text { Unit } \\
\text { price }\end{array}$ & Amount \\
\hline \multirow{2}{*}{$\begin{array}{l}\text { Wood } \\
\text { Compo- } \\
\text { nents (W) }\end{array}$} & Archi-Touch & 843.986 & 1274 & $1,075,238.16$ \\
\hline & Mobica & 1396.414 & 770 & $1,075,238.78$ \\
\hline \multirow{2}{*}{$\begin{array}{l}\text { Construc- } \\
\text { tion Wood } \\
\text { (CW) }\end{array}$} & CW-3 & 3589.8 & 450 & $1,615,410.00$ \\
\hline & CW-5 & 8376.2 & 350 & $2,931,670.00$ \\
\hline \multirow{2}{*}{$\begin{array}{l}\text { Adhesives } \\
\text { and sealants } \\
\text { (AS) }\end{array}$} & SKIA & 50.4 & 16 & 806.40 \\
\hline & $\mathrm{CMB}$ & 75.6 & 10 & 756.00 \\
\hline \multirow{2}{*}{$\begin{array}{l}\text { Paints and } \\
\text { Coatings } \\
\text { (PC) }\end{array}$} & Jotun & 433.2 & 304 & $131,692.80$ \\
\hline & Terraco & 288.8 & 202 & $58,337.60$ \\
\hline $\begin{array}{l}\text { Carpet } \\
\text { System (C) }\end{array}$ & $\begin{array}{l}\text { Style Design } \\
\text { (Interface) }\end{array}$ & 6792 & 177 & $1,202,184.00$ \\
\hline \multirow{3}{*}{$\begin{array}{l}\text { Roofing } \\
\text { System (R) }\end{array}$} & $\begin{array}{l}\text { Big white } \\
\text { gravel }\end{array}$ & 1070 & 28 & $29,960.00$ \\
\hline & Grey gravel & 802.5 & 14 & $11,235.00$ \\
\hline & $\begin{array}{l}\text { Small white } \\
\text { gravel }\end{array}$ & 802.5 & 30 & $24,075.00$ \\
\hline $\begin{array}{l}\text { Structural } \\
\text { Glazing } \\
\text { (SG) }\end{array}$ & ALICO & 5685 & 1826 & $10,380,810.00$ \\
\hline \multirow{2}{*}{$\begin{array}{l}\text { Windows } \\
\text { and } \\
\text { Skylights } \\
\text { (WS) }\end{array}$} & ALICO & 1105.5 & 1826 & $2,018,643.00$ \\
\hline & ALUNILE & 2579.5 & 1979 & $5,104,830.50$ \\
\hline \multirow{2}{*}{$\begin{array}{l}\text { Steel Doors } \\
\text { and Frames } \\
\text { (SD) }\end{array}$} & France Metal & 62.7 & 550 & $34,485.00$ \\
\hline & $\begin{array}{l}\text { Marryot\& } \\
\text { Scott }\end{array}$ & 146.3 & 500 & $73,150.00$ \\
\hline \multirow{3}{*}{$\begin{array}{l}\text { Ceiling } \\
\text { Tiles (CT) }\end{array}$} & $\begin{array}{l}\text { AL } \\
\text { BARAKA }\end{array}$ & 3232.4 & 57 & $184,246.80$ \\
\hline & I.B.S & 9697.2 & 61 & $591,529.20$ \\
\hline & $\begin{array}{l}\text { AZ Inter- } \\
\text { national }\end{array}$ & 3232.4 & 43 & $138,993.20$ \\
\hline \multirow{2}{*}{$\begin{array}{l}\text { Flooring } \\
\text { Finish (F) }\end{array}$} & Archi-Touch & 895.2 & 121 & $108,319.20$ \\
\hline & Mobica & 596.8 & 121 & $72,212.80$ \\
\hline $\begin{array}{l}\text { Structural } \\
\text { Steel (SS) }\end{array}$ & Bashy & 1696 & 3650 & $6,190,400.00$ \\
\hline \multirow{2}{*}{$\begin{array}{l}\text { Masonry } \\
\text { Units (MU) }\end{array}$} & Toblat & 4024.8 & 46 & $185,140.80$ \\
\hline & Samcret & 6037.2 & 56 & $338,083.20$ \\
\hline \multicolumn{4}{|l|}{ Total Cost } & $33,577,447.0$ \\
\hline
\end{tabular}

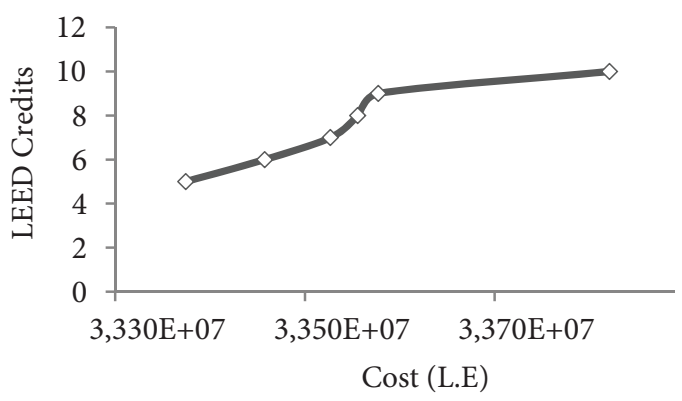

Figure 6. LEED Credits vs. Cost manner with the number of fuzzy inputs (k). A Group of scenarios is presented in Figure 5 where in each scenario some of the variables are fuzzified while the remaining variables are probabilistic. The output of the traditional Monte Carlo is shown in Figure $5(\mathrm{~K}=0)$ where there is no fuzziness associated with the constructed cumulative density function $(\mathrm{CDF})$ curve. The $\mathrm{x}$-axis represents the total cost of the project while the $y$-axis represents the probability. As the number of fuzzy inputs decreases, the bounds of CDF become smaller. Figure 5 helps the decision maker to determine the probability that the total project cost exceeds a certain number, and consequently, the decision maker can calculate the mark-up and final bid price. These curves are of great importance to decision making to make their decision with respect to the problem under consideration (Zheng et al., 2019; Wang \& Ran, 2019; Kim, 2017).

The model shows the points that represent an alternative for each level of LEED-based score as per Figure 6. A comparison between 9 and 10 credit point achieving solutions have been made; the 10 points score case comes with a substantial increase in costs, relative to the cost of achieving 9 points score. Therefore, based on cost, the 9 points solution dominates 10 points solutions. In this case, the cost criterion determined the optimum alternative. This ensures obtaining sustainable materials at minimum costs as proposed in literature (Teng et al., 2019; Chen et al. 2019; Marzouk et al., 2018).

However, material availability and delivery time should be considered when a set of alternatives would have the same number of LEED credit point. Material constraints limiting the choice of alternatives result in restricting the capacity of the model to awarded points. The Sensitivity Analysis of the FMCS optimization was conducted for different uncertain variables selected from the quantities and material prices.

\section{Conclusions}

This paper presented the implementation of a model dedicated for sustainable materials selection. The target was to achieve LEED credits taking into consideration minimizing the cost of materials. Several material alternatives have been selected and cost thereof introduced to the model as an input. In fact, the materials selected by the model proved to be more economic than those that were actually selected by the project. The proposed model helps decision makers select the most suitable materials in the design phase by optimizing project cost to achieve a specified LEED credit point. Also, it accounts for the associated uncertainties, specifically for newly introduced materials. An integrated Fuzzy Monte Carlo Simulation (FMCS) analysis was performed to account for the associated risks of using new materials. The proposed FMCS analysis is capable to represent both fuzzy and probabilistic uncertainties simultaneously. Monte Carlo simulation has been used to address probabilistic uncertainties in range estimating as well as fuzzy sets which have used to address the 
imprecise information. As such, it is considered a novel way to represent uncertainties with cost estimating of the materials that is used in construction.

\section{Disclosure statement}

The author declares he doesn't have any competing financial, professional, or personal interests from other parties.

\section{Future research perspectives}

The present study can be extended in the future to incorporate minimizing carbon dioxide emissions as a third objective function in selecting the optimum sustainable materials. This can be developed using Building Information Modeling to retrieve materials' data in an automated manner. Also, further criteria can be investigated such as the use of raw materials as well as the considered construction project type since each type has its own requirements. Further studies can cover the recent editions of rating systems such as LEED V4-US, BREEAM-UK, and GPRS-Egypt.

\section{References}

Ahuja, H. N., Dozzi, S. P., \& Abourizk, S. M. (1994). Project management: Techniques in planning and controlling construction projects. John Wiley \& Sons.

Akadiri, P. O., Olomolaiye, P. O., \& Chinyio, E. A. (2013). Multicriteria evaluation model for the selection of sustainable materials for building projects. Automation in Construction, 30, 113-125. https://doi.org/10.1016/j.autcon.2012.10.004

Antucheviciene, J., Kala, Z., Marzouk, M., \& Vaidogas, E. R. (2015). Solving civil engineering problems by means of fuzzy and stochastic MCDM methods: Current state and future research. Mathematical Problems in Engineering, 2015, 362579. https://doi.org/10.1155/2015/362579

Ashby, M. F. (2000). Multi-objective optimization in material design and selection. Acta Materialia, 48(1), 359-369. https://doi.org/10.1016/S1359-6454(99)00304-3

Castro-Lacouture, D., Sefair, J. A., Flórez, L., \& Medaglia, A. L. (2009). Optimization model for the selection of materials using a LEED-based green building rating system in Colombia. Building and Environment, 44(6), 1162-1170. https://doi.org/10.1016/j.buildenv.2008.08.009

Chan, J. W., \& Tong, T. K. (2007). Multi-criteria material selections and end-of-life product strategy: Grey relational analysis approach. Materials \& Design, 28(5), 1539-1546. https://doi.org/10.1016/j.matdes.2006.02.016

Chen, Z. S., Martínez, L., Chang, J. P., Wang, X. J., Xionge, S. H., \& Chin, K. S. (2019). Sustainable building material selection: A QFD-and ELECTRE III-embedded hybrid MCGDM approach with consensus building. Engineering Applications of Artificial Intelligence, 85, 783-807.

https://doi.org/10.1016/j.engappai.2019.08.006

Clayton, K. (1993). Confronting climatic change: Risks, implications and responses: Mintzer, I. M. (Ed.) Cambridge: Cambridge University Press, 1992. 382 pp. $£ 50$ hardback; $£ 19.95$ paperback [Book Review]. Applied Geography, 13(3), 289290. https://doi.org/10.1016/0143-6228(93)90011-O

Dubois, D., Foulloy, L., Mauris, G., \& Prade, H. (2004). Probability-possibility transformations, triangular fuzzy sets, and probabilistic inequalities. Reliable Computing, 10(4), 273-297. https://doi.org/10.1023/B:REOM.0000032115.22510.b5

Farag, M. M. (2014). Quantitative methods of materials selection. In Mechanical Engineers' Handbook (pp. 1-22). John Wiley \& Sons. https://doi.org/10.1002/9781118985960.meh115

Franzoni, E. (2011). Materials selection for green buildings: Which tools for engineers and architects? Procedia Engineering, 21, 883-890.

https://doi.org/10.1016/j.proeng.2011.11.2090

Giudice, F. L. R. G., La Rosa, G., \& Risitano, A. (2005). Materials selection in the life-cycle design process: A method to integrate mechanical and environmental performances in optimal choice. Materials \& Design, 26(1), 9-20.

https://doi.org/10.1016/j.matdes.2004.04.006

Goldstein, M. (2006). Subjective Bayesian analysis: Principles and practice. Bayesian Analysis, 1(3), 403-420. https://projecteuclid.org/euclid.ba/1340371036

Heijungs, R., Huppes, G., \& Guinée, J. B. (2010). Life cycle assessment and sustainability analysis of products, materials and technologies. Toward a scientific framework for sustainability life cycle analysis. Polymer Degradation and Stability, 95(3), 422-428.

https://doi.org/10.1016/j.polymdegradstab.2009.11.010

Holloway, L. (1998). Materials selection for optimal environmental impact in mechanical design. Materials \& Design, 19(4), 133-143. https://doi.org/10.1016/S0261-3069(98)00031-4

Jee, D. H., \& Kang, K. J. (2000). A method for optimal material selection aided with decision making theory. Materials \& Design, 21(3), 199-206.

https://doi.org/10.1016/S0261-3069(99)00066-7

Khishtandar, S. (2019). Simulation based evolutionary algorithms for fuzzy chance-constrained biogas supply chain design. Applied Energy, 236, 183-195. https://doi.org/10.1016/j.apenergy.2018.11.092

Kim, Y. J. (2017). Monte Carlo vs. Fuzzy Monte Carlo simulation for uncertainty and global sensitivity analysis. Sustainability, 9(4), 539. https://doi.org/10.3390/su9040539

Langston, C. (2008). Sustainable practices in the built environment. Routledge. https://doi.org/10.4324/9780080518251

Ljungberg, L. Y. (2007). Materials selection and design for development of sustainable products. Materials \& Design, 28(2), 466-479. https://doi.org/10.1016/j.matdes.2005.09.006

Lurie, N. H., \& Mason, C. H. (2007). Visual representation: Implications for decision making. Journal of Marketing, 71(1), 160-177. https://doi.org/10.1509/jmkg.71.1.160

Marzouk, M., Abdelhamid, M., \& Elsheikh, M. (2013). Selecting sustainable building materials using system dynamics and ant colony optimization. Journal of Environmental Engineering and Landscape Management, 21(4), 237-247. https://doi.org/10.3846/16486897.2013.788506

Marzouk, M., Azab, S., \& Metawie, M. (2018). BIM-based approach for optimizing life cycle costs of sustainable buildings. Journal of Cleaner Production, 188, 217-226. https://doi.org/10.1016/j.jclepro.2018.03.280

Menassa, C. C. (2011). Evaluating sustainable retrofits in existing buildings under uncertainty. Energy and Buildings, 43(12), 3576-3583. https://doi.org/10.1016/j.enbuild.2011.09.030

Pedrycz, W., \& Gomide, F. (1998). An introduction to fuzzy sets: Analysis and design. Mit Press. https://doi.org/10.7551/mitpress/3926.001.0001

Peña, A., Bonet, I., Lochmuller, C., Chiclana, F., \& Góngora, M. (2018). An integrated inverse adaptive neural fuzzy system with Monte-Carlo sampling method for operational risk management. Expert Systems with Applications, 98, 11-26. https://doi.org/10.1016/j.eswa.2018.01.001 
Raoufi, M., Seresht, N. G., \& Fayek, A. R. (2016, October). Overview of fuzzy simulation techniques in construction engineering and management. In Fuzzy Information Processing Society (NAFIPS), 2016 Annual Conference of the North American (pp. 1-6). El Paso, TX, USA. https://doi.org/10.1109/NAFIPS.2016.7851610

Robati, M., Daly, D., \& Kokogiannakis, G. (2019). A method of uncertainty analysis for whole-life embodied carbon emissions $\left(\mathrm{CO}_{2}-\mathrm{e}\right)$ of building materials of a net-zero energy building in Australia. Journal of Cleaner Production, 225, 541-553. https://doi.org/10.1016/j.jclepro.2019.03.339

Sadeghi, N., Fayek, A. R., \& Pedrycz, W. (2010). Fuzzy Monte Carlo simulation and risk assessment in construction. Computer-Aided Civil and Infrastructure Engineering, 25(4), 238252. https://doi.org/10.1111/j.1467-8667.2009.00632.x

Sameer, H., \& Bringezu, S. (2019). Life cycle input indicators of material resource use for enhancing sustainability assessment schemes of buildings. Journal of Building Engineering, 21, 230-242. https://doi.org/10.1016/j.jobe.2018.10.010

Sirisalee, P., Ashby, M. F., Parks, G. T., \& Clarkson, P. J. (2004). Multi-criteria material selection in engineering design. Advanced Engineering Materials, 6(1-2), 84-92. https://doi.org/10.1002/adem.200300554

Teng, J., Mu, X., Wang, W., Xu, C., \& Liu, W. (2019). Strategies for sustainable development of green buildings. Sustainable Cities and Society, 44, 215-226. https://doi.org/10.1016/j.scs.2018.09.038

USGBC. (2009). LEED - Leadership in energy and environmental design: Green building rating system, V.3.0. US Green Building Council.
Wang, W., Rivard, H., \& Zmeureanu, R. (2005). An object-oriented framework for simulation-based green building design optimization with genetic algorithms. Advanced Engineering Informatics, 19(1), 5-23.

https://doi.org/10.1016/j.aei.2005.03.002

Wang, Y., \& Ran, W. (2019). Comprehensive eutrophication assessment based on fuzzy matter element model and Monte Carlo-triangular fuzzy numbers approach. International Journal of Environmental Research and Public Health, 16(10), 1769. https://doi.org/10.3390/ijerph16101769

WCED. (1987). Report of the World Commission on environment and development: Our common future. http://www.un-documents.net/our-common-future.pdf

Zadeh, L. A. (1965). Fuzzy sets. Information and Control, 8(3), 338-353. https://doi.org/10.1016/S0019-9958(65)90241-X

Zheng, D., Yu, L., Wang, L., \& Tao, J. (2019). Integrating willingness analysis into investment prediction model for large scale building energy saving retrofit: Using fuzzy multiple attribute decision making method with Monte Carlo simulation. Sustainable Cities and Society, 44, 291-309. https://doi.org/10.1016/j.scs.2018.10.008

Zhou, C. C., Yin, G.-F., \& Hu, X.-B. (2009). Multi-objective optimization of material selection for sustainable products: Artificial neural networks and genetic algorithm approach. Materials \& Design, 30(4), 1209-1215. https://doi.org/10.1016/j.matdes.2008.06.006 